\title{
BMJ Open Dietary intake, physical activity and muscle strength among adolescents: the Malaysian Health and Adolescents Longitudinal Research Team (MyHeART) study
}

\author{
Ai Kah Ng, ${ }^{1,2}$ Noran Naqiah Hairi, ${ }^{3}$ Muhammad Yazid Jalaludin, ${ }^{4}$ \\ Hazreen Abdul Majid ${ }^{\oplus, 5,6}$
}

To cite: $\mathrm{Ng}$ AK, Hairi NN, Jalaludin MY, et al. Dietary intake, physical activity and muscle strength among adolescents: the Malaysian Health and Adolescents Longitudinal Research Team (MyHeART) study. BMJ Open 2019;9:e026275. doi:10.1136/ bmjopen-2018-026275

\section{- Prepublication history for} this paper is available online. To view these files, please visit the journal online (http://dx.doi. org/10.1136/bmjopen-2018026275).

Asian Congress of Dietetics (ACD) on $7^{\text {th }}$ Jul 2018 at Hong Kong. Title: Association between dietary intakes and hand grip strength among adolescents:The Malaysian Health and Adolescents Longitudinal Research Team Study (theMyHeARTs Study)

Received 30 August 2018 Revised 31 May 2019 Accepted 3 June 2019

\section{Check for updates}

(C) Author(s) (or their employer(s)) 2019. Re-use permitted under CC BY-NC. No commercial re-use. See rights and permissions. Published by BMJ.

For numbered affiliations see end of article.

\section{Correspondence to} Associate Prof. Hazreen Abdul Majid;

hazreen@um.edu.my

\section{ABSTRACT}

Objective To examine the role of dietary intake and physical activity in muscle strength among adolescents.

Design Cross-sectional analysis.

Setting The Malaysian Health and Adolescents Longitudinal Research Team (MyHeART) study.

Participants Fifteen-year-old secondary school children who have given consent and who participated in the MyHeART study in 2014.

Primary outcome measure Muscle strength was measured in relation to dietary intake (energy and macronutrients) and physical activity by using a hand grip dynamometer.

Results Among the 1012 participants (395 male; 617 female), the hand grip strength of the males was higher than that of the females $(27.08 \mathrm{~kg}$ vs $18.63 \mathrm{~kg} ; \mathrm{p}<0.001)$. Also, males were more active (2.43vs2.12; $p<0.001)$ and consumed a higher amount of energy (2047 kcal vs $1738 \mathrm{kcal} ; \mathrm{p}<0.001)$, carbohydrate (280.71 g vs $229.31 \mathrm{~g}$; $\mathrm{p}<0.001)$ and protein $(1.46 \mathrm{~g} / \mathrm{kg}$ body weight $(B W)$ vs $1.35 \mathrm{~g} / \mathrm{kg} \mathrm{BW} ; \mathrm{p}<0.168)$. After controlling for ethnicity, place of residency and body mass index, there was a positive relationship between hand grip strength and the intake of energy $(r=0.14 ; p=0.006)$, carbohydrate $(r=0.153 ; p=0.002)$ and fat $(r=0.124 ; p=0.014)$ and the physical activity score $(r=0.170 ; p=0.001)$ and a negative relationship between hand grip strength and the intake of protein $(r=-0.134 ; p=0.008)$, for males. However, this was not observed among females.

Conclusions Energy, carbohydrate and fat intakes and physical activity score were positively correlated with hand grip strength while protein intake was negatively correlated with hand grip strength in males but not in females.

\section{INTRODUCTION}

Recent research has paid much attention to poor muscle strength among adolescents and its association with adverse health-related outcomes, including cardiovascular disease, ${ }^{1}$ poorer metabolic profile, ${ }^{2-4}$ obesity $^{56}$ and musculoskeletal pain ${ }^{7}$ as well as premature
Strengths and limitations of this study

- The main strengths of this study are that it used a large sample of adolescents and the standardised measurement of muscle strength.

- This study is also the first to investigate the association between dietary intake, physical activity and muscle strength among adolescents in Asia.

- The main limitations of this study are that the sample covers a limited age range and the cross-sectional design of the study does not allow any causality interpretations.

death from any cause. ${ }^{1}$ Furthermore, a cross-sectional study among adolescents in a city in southern Brazil reported a prevalence of low muscle strength of $47 \%$ among the study population. ${ }^{8}$ Moreover, most studies have suggested that there is a declining trend of muscle strength among adolescents over time ${ }^{9-12}$ except for a study conducted in Colombia ${ }^{13}$ that indicated otherwise. The study in Colombia, a middle-income country, also found that adolescents have a lower hand grip strength compared with those in high-income countries. ${ }^{13}$ Similarly, a preliminary finding from the Malaysian Health and Adolescents Longitudinal Research Team (MyHeART) study showed that Malaysian adolescents have a lower hand grip strength than those in other countries. ${ }^{914}$ However, it was not possible to categorise the hand grip strength of Malaysian adolescents based on the cut-off values used ${ }^{8}$ as there were no available normal values for Asian adolescents. Moreover, the published cut-off values should not be used as the reference standard for Asian populations because most Asians are not able to achieve the published cut-off values. $^{16}$ 
Issues pertaining to unhealthy dietary intake ${ }^{17}$ and low physical activity ${ }^{18}$ among adolescents are well documented worldwide. In fact, dietary intake and/or low physical activity are increasingly recognised to be modifiable health-related behavioural determinants of muscle strength among adolescents. ${ }^{15}$ 19-21 The results reported by population-based cohort studies regarding the effect of energy and macronutrient intake are limited at this point in time. ${ }^{152}$ For instance, a cross-sectional study that was conducted among European adolescents found that specific amino acids are associated with muscle strength; however, when carbohydrate is controlled for, these relationships disappear. ${ }^{15}$ Another cohort study from India in which pregnant women and children were given a balanced protein-calorie supplementation and the children were followed up at adult stage also emphasised the importance of an adequate energy intake in order to increase muscle strength. The cohort study also found that energy intake and physical activity are positively associated with muscle strength. ${ }^{22}$ Furthermore, an experimental study on adolescents found that milk supplementation with resistance training does not change body composition. ${ }^{23}$ However, the authors argued that it could be due to energy intake playing a vital role in the relationship between body composition, resistance training and the effect of these factors on both muscle mass and strength. ${ }^{23}$

In view of the changes that take place in the skeletal muscle in response to energy and macronutrient intake particularly carbohydrate and protein intake, in normal physiology, ${ }^{24}$ it is worthwhile to further investigate the relationship between dietary intake, particularly energy and macronutrients, and muscle strength. While previous studies have provided some evidences to demonstrate that low level of physical activity ${ }^{825}$ and being overweight ${ }^{8}$ are associated with low hand grip strength, there was only a study by Gracia-Marco $e t a l^{15}$ that has evaluated the effect of amino acids (dietary protein) and physical activity on hand grip strength. It seems that no study has evaluated the influence of dietary intake and physical activity on hand grip strength among adolescents specifically. Thus, the relationship between dietary intake, physical activity and muscle strength among adolescents is not yet well understood. Moreover, to the best of the authors' knowledge, only a limited number of studies have investigated the association between hand grip strength, dietary intake and/or physical activity among adolescents, particularly in Asia. Therefore, the purpose of this paper is to examine the association between hand grip strength, dietary intake and physical activity among adolescents in Malaysia.

\section{METHODS}

This cross-sectional study is a secondary analysis of data derived from the first follow-up of the MyHeART study. The population for the current study was composed of 15-year-old adolescents attending public secondary schools in the central and northern regions of Peninsular Malaysia. The sampling method used was multistage random sampling. The primary sampling units were the schools and the secondary sampling units were the students. In the first stage, the study frame was a complete list of public schools in the two aforementioned regions from which a total of 15 public secondary schools were selected. In the second stage, the defined study population was selected from a complete list of Form Three students in each of the selected school. Full details of the original MyHeART study protocol have been published elsewhere. $^{26}$

An information sheet and consent forms were given to the students and their parents/guardian prior to recruitment. Participation in the study was on a voluntary basis. In 2014, 1230 adolescents were recruited for the MyHeART study. Out of the total participants in 2014, $1012(82.3 \%)$ were included in the analysis for this paper. A flowchart of the sampling procedure used to select the participants for this study is provided in figure 1 .

Subsequently, formal approval was obtained from the Ministry of Health and Ministry of Education and then approval was sought from the relevant state-level administrative authorities before approaching the Headmasters and Headmistresses of the selected schools.

The data collection was conducted by the MyHeART team, which was led by the principal investigator. The team consisted of 20 research assistants (medical doctors, nurses and dietitians) who collected the data at various stations such as anthropometry, hang grip strength and dietary stations. The data were collected between March and May in 2014. Prior to conducting data collection, the principal investigator provided orientation and training sessions for the research assistants in order to familiarise them with the objectives and methodology of the study as well as hands-on practice in measuring the anthropometrics and hand grip strength. In addition, the research assistants who were dietitians received training on how to conduct the 7-day diet history using standardised portion of food and how to translate the diet history into a coding sheet in order to ensure the consistency and quality of the collected data.

\section{Muscle strength}

Hand grip strength has been shown to have moderate to strong validity and high reliability in tests for upper body and lower body strength in adolescents. ${ }^{27}$ Moreover, hand grip strength has been found to be valid, reliable and feasible for school setting. ${ }^{28}$ Therefore, muscle strength was assessed by using hand grip strength. A calibrated hand dynamometer (Jamar; Sammons Preston Rolyan, Bolingbrook, Illinois, USA), whose unit of measurement is the kilogram, was used in the assessment of hand grip strength. The strength of the dominant and the non-dominant hand was recorded. Prior to the measurements being taken, the dynamometer was calibrated. Then, it was adjusted for different hand sizes. Participants were gathered in a hall. The hand grip strength measurement 


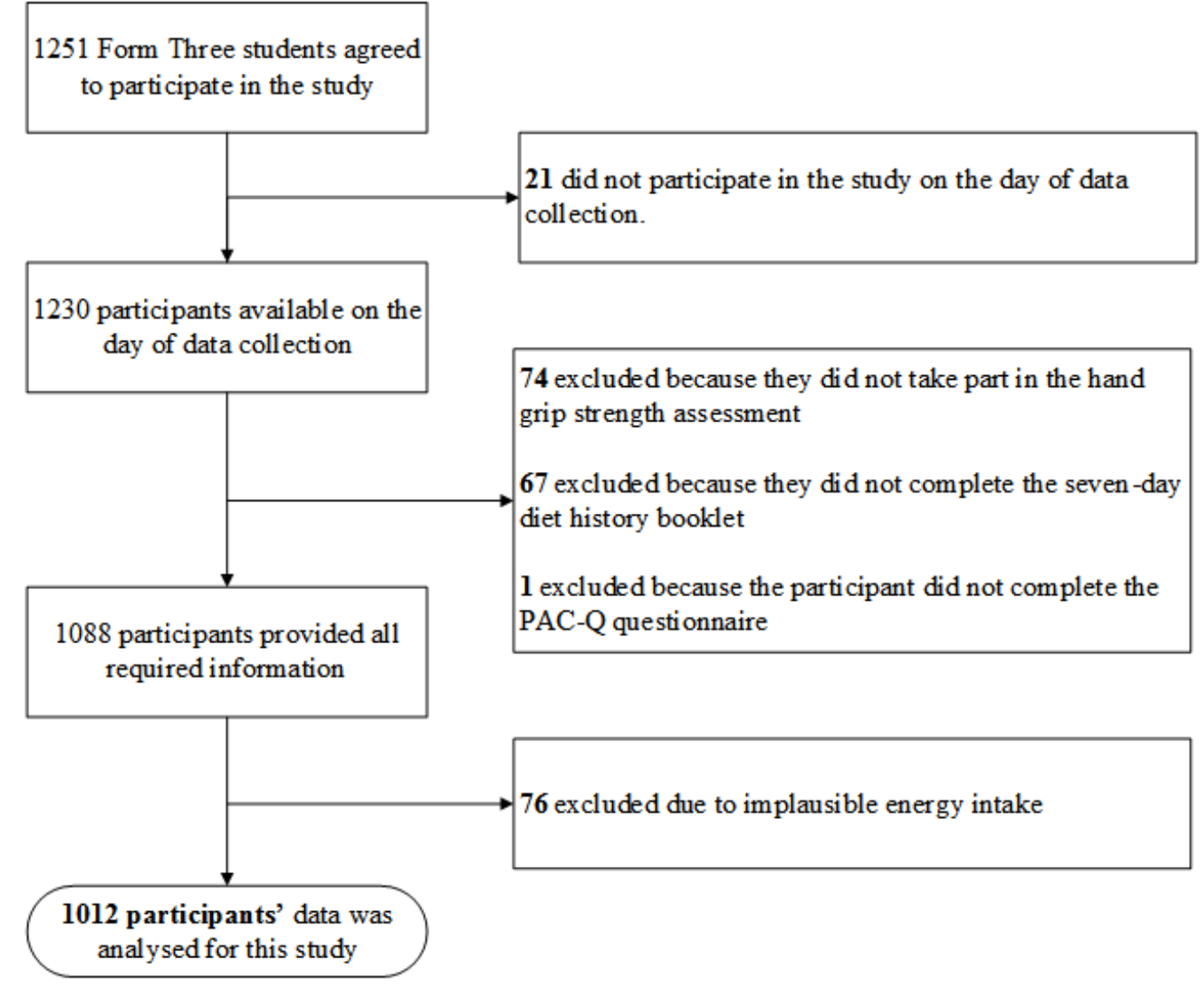

Figure 1 Flowchart of the participant sampling procedure. PAQ-C, Physical Activity Questionnaire for Older Children.

was taken in the morning before afternoon (between 10:00 and 12:00). Each participant was positioned in a straight back chair with both feet flat on the ground. The elbow was flexed to 90 degrees with forearm and wrist in neutral position. The measurement began with the dominant hand once the dominant hand was identified. The measurement was followed by the non-dominant hand. The dominant and non-dominant hands of the participants were each tested three times and the readings were recorded to the nearest $0.1 \mathrm{~kg} .{ }^{29}$ The average of the three readings for the dominant hand was used in analysis. All the measurements were done by trained research assistants.

\section{Dietary intakes}

Dietary intake was assessed by using a 7-day diet history. The diet history is the best method by which to estimate adolescents' intakes because they can better recall what they have eaten and drunk and this history can thus reveal more accurate information about their overall intakes. ${ }^{30}$ This method also shows less variation in dietary assessment from the epidemiological perspective ${ }^{31}$ and is more representative of adolescents' habitual intakes than other methods. $^{32} 33$ The 7-day diet history was collected by trained research assistants who were qualified dietitians. The Nutrient Composition of Malaysian Food (fourth edition) ${ }^{34}$ was used to calculate energy and macronutrient intakes and the values were entered into the Nutritionist Pro database (Axxya Systems, Stafford, Texas, USA). ${ }^{34}$
The intakes from food items and recipes that could not be found in the Nutrient Composition of Malaysian Food were calculated on the basis of the details provided by the food packaging and the recipe. These calculations were then entered into the database by adjusting them based on standard recipes (per serving size). After the diet history had been analysed, $10 \%$ of the data were randomly crosschecked by an independent qualified dietitian who was not involved in analysing the dietary data. The margin of error was $4.4 \%$. It was seemed acceptable as it has been stated that a $10 \%$ margin of error is acceptable. ${ }^{35}$ Total of 76 participants with implausible energy intakes $(<500 \mathrm{kcal} /$ day or $>5000 \mathrm{kcal} /$ day $)$ were excluded from this analysis. ${ }^{36}$

\section{Physical activity score}

A Malay version of the validated Physical Activity Questionnaire for Older Children (PAQ-C) consisting of 10 items was used to obtain the physical activity level of the adolescents over the past 7 days. The PAQ-C questionnaire has been shown to be valid and to have good internal consistency. ${ }^{37-39}$ The translated version has been validated in a local setting. ${ }^{40}$ The first item in the questionnaire was used to assess the type and frequency of sports and/or dance activities in which the adolescents took part. The second to eighth were used to assess the activity of the adolescents during physical education classes, recess, lunchtime, immediately after school, in the evenings, at the weekend and during leisure time. A five-point Likert 
scale 1 (lowest) to 5 (highest) was used for the second to eighth items. The ninth item was used to assess their physical activity frequency. The 10 th item was used to gather information on any unusual activities that the adolescents undertook during those 7 days. The results obtained from the PAQ-C were categorised following Crocker et $a t^{41}$ (1997) into low (<2.33), moderate (2.33-3.66) and high (>3.66).

\section{Anthropometric measures}

Body weight was measured by using a digital electronic weighing scale (Seca 813; Seca, Birmingham, UK) and recorded to the nearest $0.1 \mathrm{~kg}$. Height was measured without socks and shoes by using a calibrated vertical stadiometer (Seca Portable 217; Seca) and recorded to the nearest $0.1 \mathrm{~cm}$. Body mass index (BMI) was calculated as weight in kilograms divided by the square of height in metres. Waist circumference (midpoint between the lowest rib margin and the iliac crest) was measured by using a non-elastic measuring tape (Seca 201; Seca) and recorded to the nearest $0.1 \mathrm{~cm}$. Percentage body fat was measured by using a bioelectric impedance analyser (SC-240 Body Composition Analyser; Tanita Europe BV, Amsterdam, The Netherlands).

\section{Sociodemographic measures}

Sociodemographic measures were collected via parental and student questionnaires which included questions on age, ethnicity and place of residency.

\section{Statistical analyses}

Analyses were performed using the SPSS software for Windows V.22.0, and the significance level was set at $p$ value $<0.05$. The analyses were performed separately by gender. Normality and skewness tests were used to assess normal distribution. All variables showed a normal distribution, except for weight, waist circumference and BMI. Data were presented as means and SD for normally distributed continuous variables, medians and IQRs for non-normally distributed continuous variables and percentages for categorical variables. The independent t-test was used to examine gender differences for normally distributed variables and the Mann-Whitney $\mathrm{U}$ test was used for non-normally distributed variables. The association between hand grip strength and (1) energy intake, (2) macronutrient intake and (3) physical activity score was assessed by using Pearson's correlation coefficient. The hand grip strength of the dominant hand was entered as the dependent variable and (1) energy and macronutrient intake and (2) physical activity score were entered as the independent variables while controlling for ethnicity, place of residency and BMI. BMI was chosen as the covariate despite there being several other indicators of obesity because BMI is able to discriminate body fatness in adolescents. ${ }^{42}$ In addition, linear regression was used to investigate whether dietary intake and physical activity could predict hand grip strength when controlling for ethnicity, place of residency and BMI.

\section{Patient and public involvement}

This is a prospective adolescent cohort study from general population; therefore, there was no patient involvement in this study. In this study, all eligible students were briefed on the purpose of the study, the benefits of the study and any potential harm for them. The individual results such as weight, height, waist and hip circumference, and hand grip strength were recorded into individual health information leaflets, and this information was given back to the students on the same day of data collection. Once other results on full blood counts, renal profile, fasting blood glucose and lipid profile were returned to the investigators, the results were verified by a paediatrician and disseminated to the students' parents. Any of the results that went beyond the clinical reference ranges, the student and parents were informed and referred to either the nearest government clinic or University of Malaya's outpatient paediatric clinic for further treatment. Besides that, study findings will be disseminated through media interview, printed media and presentation to the Ministry of Education and Ministry of Health, Malaysia.

\section{RESULTS}

\section{Descriptive analysis}

Table 1 provides the characteristics of the participants. It can be seen that males had significantly higher values than females in terms of weight, physical activity score, hand grip strength of both hands, and energy and carbohydrate intakes per day, but not in percentage body fat and BMI $(p<0.05)$. About two-thirds $(69.2 \%)$ of the females had a low physical activity score, whereas almost two-thirds of the males $(65.2 \%)$ had a moderate to high physical activity score.

\section{Correlation and regression}

Table 2 illustrates the main result and the number of participants used for the analysis which was as described in figure 1. A positive linear relationship was found between energy, carbohydrate, and fat intakes and physical activity score and the dependent variable hand grip strength $(\mathrm{p}<0.01)$ among males. Meanwhile, protein $(\mathrm{g} /$ $\mathrm{kg}$ body weight) was found to be negatively correlated with hand grip strength among males $(\mathrm{p}<0.01)$. However, no such correlation was found in females.

To investigate whether dietary intake and physical activity could predict hand grip strength, a linear regression was computed while controlling for ethnicity, place of residency and BMI. Before running the regressions, the assumptions of linearity, normally distributed errors and non-correlated errors were checked and met. Protein, carbohydrate and fat intakes were not used in the regression due to multicollinearity. When the physical activity score and energy intake were added, both variables significantly predicted hand grip strength: $\mathrm{F}(3,391)=26.318, \mathrm{p}<0.001$, adjusted $\mathrm{R}^{2}=0.162$ (table 3 ). When physical factors (length of dominant hand span 
Table 1 Characteristics of MyHeART participants

\begin{tabular}{|c|c|c|c|c|}
\hline & $\begin{array}{l}\text { Male } \\
(n=395)\end{array}$ & $\begin{array}{l}\text { Female } \\
(n=617)\end{array}$ & $\begin{array}{l}\text { All } \\
(n=1012)\end{array}$ & $P$ value \\
\hline Age (years) & $15.04( \pm 0.198)$ & $15.04( \pm 0.205)$ & $15.04( \pm 0.202)$ & 0.384 \\
\hline \multicolumn{5}{|l|}{ Ethnicity } \\
\hline Malay & $307(77.7 \%)$ & $487(78.9 \%)$ & $795(78.6 \%)$ & 0.495 \\
\hline Chinese & $26(6.6 \%)$ & $47(7.6 \%)$ & $73(7.2 \%)$ & \\
\hline Indian & $35(8.9 \%)$ & $54(8.8 \%)$ & $89(8.8 \%)$ & \\
\hline \multicolumn{5}{|l|}{ Place of residency } \\
\hline Urban & $216(54.7 \%)$ & $367(59.5 \%)$ & $583(57.6 \%)$ & 0.132 \\
\hline Rural & $179(45.3 \%)$ & $250(40.5 \%)$ & $429(42.4 \%)$ & \\
\hline Weight* (kg) & $51.00(17.00)$ & $48.50(15.35)$ & $49.50(15.60)$ & $<0.001^{*}$ \\
\hline Underweight & $86(21.8 \%)$ & $108(17.5 \%)$ & $194(19.2 \%)$ & \\
\hline Normal & $222(56.2 \%)$ & $355(57.5 \%)$ & $577(57.0 \%)$ & \\
\hline Overweight & $51(12.9 \%)$ & $101(16.4 \%)$ & $152(15.0 \%)$ & \\
\hline Obesity & $36(9.1 \%)$ & $53(8.6 \%)$ & $89(8.8 \%)$ & \\
\hline$\%$ Body fat & $15.50( \pm 11.02)$ & $29.37( \pm 9.17)$ & $23.95( \pm 12.01)$ & $<0.001^{\star}$ \\
\hline Waist circumference* $(\mathrm{cm})$ & $67.90(15.50)$ & $69.00(13.50)$ & $68.50(14.00)$ & 0.514 \\
\hline Physical activity score & $2.43( \pm 0.75)$ & $2.12( \pm 0.54)$ & $2.24( \pm 0.65)$ & $<0.001^{*}$ \\
\hline \multicolumn{5}{|l|}{ Physical activity level } \\
\hline $\operatorname{Low}(<2.33)$ & $177(44.8 \%)$ & $427(69.2 \%)$ & $604(59.7 \%)$ & $<0.001^{*}$ \\
\hline \multicolumn{5}{|l|}{ Energy and macronutrient intake } \\
\hline Energy (kcal) & $2047( \pm 583)$ & $1738( \pm 474)$ & $1858( \pm 540)$ & $0.001^{*}$ \\
\hline Protein (g) & $75.69( \pm 22.48)$ & $66.07( \pm 19.45)$ & $69.82( \pm 21.20)$ & $0.04^{*}$ \\
\hline Protein $(\mathrm{g} / \mathrm{kg})$ & $1.46( \pm 0.58)$ & $1.35( \pm 0.53)$ & $1.40( \pm 0.55)$ & 0.168 \\
\hline Carbohydrate (g) & $280.71( \pm 90.17)$ & $229.31( \pm 67.79)$ & $249.37( \pm 81.23)$ & $<0.001^{*}$ \\
\hline Fat $(\mathrm{g})$ & $68.97( \pm 21.74)$ & $61.60( \pm 20.13)$ & $64.48( \pm 21.07)$ & 0.16 \\
\hline
\end{tabular}

Differences between male and female participants were determined using an independent t-test and the Mann-Whitney $U$ test. Data are presented as means \pm SD or as $n(\%)$, unless otherwise stated.

*Values are expressed as medians (IQRs).

†Statistically significant at $p<0.05$.

and height) were entered, the prediction improved with an adjusted $R^{2}$ of 0.339 .

\section{DISCUSSION}

Hand grip strength, dietary intake and physical activity

This study showed that the muscle strength of Malaysian adolescents is much lower than that of their counterparts as reported by studies in Europe (males: $35.9 \pm 9.3 \mathrm{~kg}$; females: $26.2 \pm 4.9 \mathrm{~kg}$ ), the UK (males: $25.7 \pm \mathrm{kg}$; females: $21.8 \pm 5.8 \mathrm{~kg}$ ) and Colombia of South America (males:
$33.6 \pm 6.85 \mathrm{~kg}$; females: $24.9 \pm 4.29 \mathrm{~kg}){ }^{2}{ }^{21543}$ Also, according to the results, female adolescents in Malaysia have lower muscle strength than those in Beijing, China. ${ }^{44}$ Unfortunately, there are no large population-based Asian male adolescent data with which to compare with the results of the current study. Hence, this study can be considered the first documented muscle strength study among adolescents of both genders in Asia. Nevertheless, despite the lack of comparable studies, the trend for adolescents is similar to that reported for Malaysian adult population, 
Table 2 Partial correlation $(r)$ between dietary intake, physical activity score and hand grip strength in adolescents

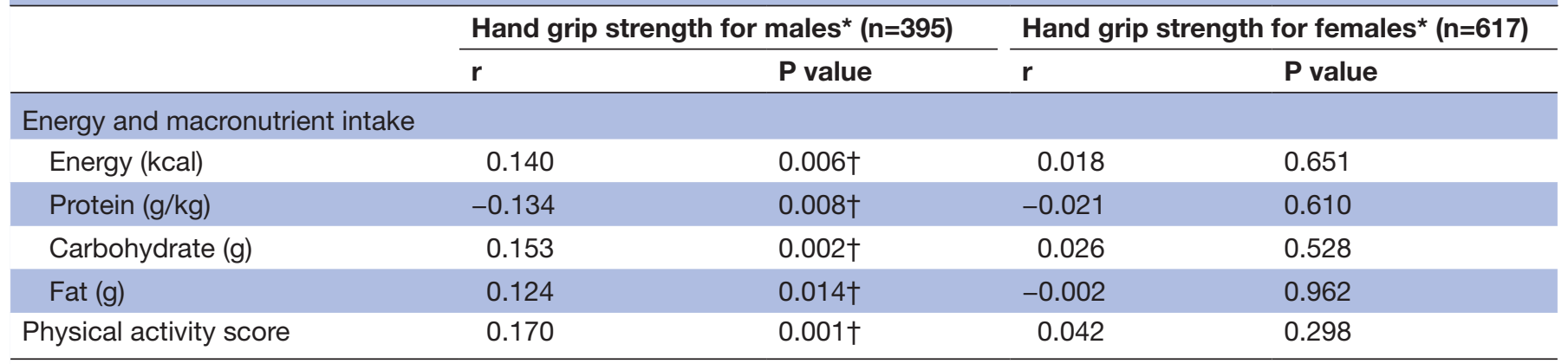

*Controlled for ethnicity, place of residency and body mass index. †Statistically significant at $\mathrm{p}<0.05$.

where it was found that the hand grip strength of Malaysian adults is 1.5 times lower than that of adults in western countries. ${ }^{45}$ Thus, together with the findings of the current study, this may indicate that the muscle strength of the Malaysian population is relatively low from a young age. Indeed, the results of a longitudinal study conducted in Quebec, a province in eastern Canada, which tracked muscle strength from childhood to adulthood, suggested that low muscle strength can persist from childhood through adolescence and into adulthood. ${ }^{46}$ Therefore, it seems worthwhile to detect low muscle strength at a young age and build it up in order to foster favourable health outcomes in later life. ${ }^{1}$ Thus, it can be argued that low muscle strength among adolescents warrants particular attention in order to identify the root cause, especially if it is associated with dietary intake and physical activity which are both modifiable health-related behaviours.

The results of this study also showed that there were differences in hand grip strength, dietary intake and physical activity score between male and female adolescents. Specifically, the males had higher muscle strength; consumed more energy, protein and carbohydrate; and were more physically active than their female counterparts. These findings are consistent with those of previous studies conducted on study populations aged 13 years. ${ }^{1477} 48$

\section{Association between dietary intake, physical activity and hand grip strength}

In this study, in males, energy, carbohydrate and fat intakes, and physical activity score were positively correlated with hand grip strength, but protein was

Table 3 Multiple linear regression model for male adolescents

\begin{tabular}{llll}
\hline & \multicolumn{3}{l}{$\begin{array}{l}\text { Hand grip strength of male } \\
(\mathbf{n}=395)\end{array}$} \\
\cline { 2 - 4 } & $\mathbf{R}^{2}$ & $\boldsymbol{\beta}$ & $\mathbf{P}$ value \\
\hline & 0.162 & & \\
\hline Energy intake (kcal) & & 0.143 & $0.002^{*}$ \\
\hline Physical activity score & & 0.129 & $0.006^{*}$ \\
\hline
\end{tabular}

${ }^{*}$ Controlled for ethnicity, place of residency and body mass index. negatively weak correlated (table 2). Although it has been shown that protein helps muscle protein synthesis and thus eventually improves muscle strength ${ }^{49}$ the effect of protein was not observed in this study. One possible explanation for this finding could be due to the quality of protein consumed.$^{50}$ Often, dietary protein is ingested as a whole so it includes high biological value and low biological value, and this leads to difficulty in identifying how proteins derived from animal and plant sources differ in their capacity to improve muscle mass and strength. Empirical studies have shown that at least $25 \mathrm{~g}$ of high-quality proteins (including at least $8-10 \mathrm{~g}$ essential amino acids and higher leucine content) promote muscle protein synthesis and thus result in better muscle strength. ${ }^{49}$ Therefore, the specific impact of high-biological-value protein is worth investigating in the future.

In addition, studies have also reported that energy plays a moderating role in muscle strength. ${ }^{22}{ }^{23}$ Although a study that used milk supplementation and resistance training as an intervention did not see an improvement in muscle mass, the researchers argued that energy plays a mediator role in the relationship between muscle mass, protein intake and resistance training despite the finding showing otherwise. ${ }^{23}$ Therefore, a sufficient intake of energy and/or carbohydrate to meet the daily requirement is needed before protein can play a role in promoting muscle building and strength.

In the current study, when the energy intake per day and physical activity score were added into the model while controlling for BMI, both of these predictors remained significantly associated with hand grip strength. In addition, a higher energy intake and a higher physical activity score predicted a higher hand grip strength. Moreover, a higher BMI predicted a higher hand grip strength. The latter finding is consistent with that reported by a study on Southern Brazil adolescents, which found that the higher the BMI, the greater the muscle strength. ${ }^{21}$ Also, the researchers stated that their study population had a higher body mass, particularly muscle. As the current study did not include an objective measure for muscle mass, we considered body fat percentage and it was found that the male participants had a lower body fat 
percentage than the female participants. In addition, the average BMI of the (15-year-old) male participants was below the overweight level using International Obesity Task Force reference. Nevertheless, BMI is not generally regarded as a good indicator of body composition..$^{51}$ In this study, body fat percentage showed similar result after percentage body fat was used in the model to replace BMI. With that, the usage of BMI remained for easier comparison with other studies. On the other hand, there is a general consensus that the higher the body fat, especially abdominal fat, the lower the hand grip strength. ${ }^{5}$ This could be due to fat playing an inert role in muscle strength. ${ }^{52}$ However, in contrast to the aforementioned studies, a study conducted in Italy on a sample of 2411 adolescents produced a neutral result, implying that obesity does not affect muscle strength among healthy schoolchildren..$^{53}$ Nonetheless, the predictive equation used in the current study needs to be interpreted with caution as energy intake and physical activity only explain about $16.2 \%$ of the variation in muscle strength.

In this study, no relationship was found between dietary intake, physical activity score and hand grip strength among female adolescents. This result is similar to that reported in a study on adolescents in Europe ${ }^{15}$ which showed that proline (amino acids) is positively correlated with lower limb muscular strength but that, when carbohydrate intake is controlled for, this relationship disappears. ${ }^{15}$ On the other hand, a study conducted among Kenya adolescents found that female adolescents have greater muscle strength than their male counterparts and suggested that this was because the females undertake more household chores such as transferring water from deep wells and preparing meals, and thus have greater access to food than the males. ${ }^{54}$ All such activities eventually help to build upper limb muscle strength. However, these conditions are not commonly found in Malaysia where most adolescents are school attendees. It is therefore postulated that the reason that female adolescents in this study had lower muscle strength than the males is because almost $70 \%$ of the females had a low physical activity score due to a predominantly sedentary lifestyle as compared with the males, $65 \%$ of whom had a moderate to high physical activity score. It has also been found by a previous study that females already have a lower physical activity score at an earlier age compared with males ${ }^{47}$ and that this continues as they age.

Another possible reason for the significant result observed in males but not females could be due to changes with puberty stage, where the hand grip strength of males increases tremendously at this stage as compared with females. A study has reported that at 13 years old, the hand grip strength of males and females is $17.8 \mathrm{~kg}$ and $14.7 \mathrm{~kg}$, respectively. ${ }^{14}$ Greater muscle hypertrophy is commonly found in pre-adolescent males compared with females at the same growth stage because of increasing levels of circulating androgens in the males. ${ }^{55}$ Moreover, it has also been found that muscle strength increases when a male reaches puberty, which it has been argued is related to the growth spurt due to the direct action of testosterone, which has a direct anabolic effect on muscle fibres. ${ }^{56}$ In the population analysed in the current study, the majority (95\%) of the males has reported that they had reached the puberty stage. Thus, in addition to the males being moderately to highly physically active, the presence of testosterone could explain the marked difference in muscle strength between the male and female participants.

Although a positive effect of protein on muscle strength was not seen in this study, it is still crucial to explore the effect of dietary protein as it is known to play a role in ensuring appropriate growth during adolescence. ${ }^{15}$ Furthermore, muscle building only occurs when a person is physically active because such activity triggers the digestion and better absorption of amino acids, ${ }^{5057}$ which eventually increases muscle strength. Moreover, it is crucial to ensure that energy and carbohydrate intake requirements are met before protein can even play a role in improving muscle strength. The above findings therefore indicate that there is a strong need to undertake a longitudinal study to explore whether changes in dietary intake have an impact on hand grip strength among adolescents, and such a study also needs to takes into account the variables of physical activity and weight status.

It is also important to acknowledge that the type of physical activity can affect the hand grip strength. A cross-sectional study has suggested different types of physical activity influence hand grip strength and not the amount of time spent on physical activity. ${ }^{58}$ Often, studies on muscle strength have included obesity parameters such as BMI and percentage body fat. Some of these studies have found that obese adolescents exhibit lower relative muscle strength to body mass as compared with their non-obese counterparts. ${ }^{62}$ Some studies have found otherwise. ${ }^{85359}$ For instance, one such study reported that girls with normal BMI have a low hand grip strength as compared with overweight/obese girls, ${ }^{8}$ and the author postulated that the overweight/obese females may have increased their muscle mass due to physical growth. However, this findings and postulation needs to be interpreted cautiously because BMI does not differentiate between fat mass and fat-free mass. Moreover, the finding of that study could be due to discrepancies when examining the absolute strength and muscle strength relative to muscle mass and muscle quality. Besides dietary and physical activity factors, the literature has also shown that physical factors such as height and length of hand span can influence hand grip strength. ${ }^{21} 6061$ Although assessing the influence of physical factors was not one of this study's objectives, physical factors were found to play a role in influencing hand grip strength.

\section{Strengths and limitations}

This study has a number of strengths. First, it was conducted using a large sample of adolescents. Second, it used the standard protocols for hand grip strength, dietary intake and physical activity assessment as well as 
data monitoring processes during data collection, data entry and data analysis in order to minimise the risk of bias. Moreover, to the best of the authors' knowledge, this study may be the first to investigate the association between hand grip strength, dietary intake and physical activity among adolescents in Asia. However, it should be noted that this study is somewhat limited because it was cross-sectional in design, so the presence or otherwise of a causal relationship could not be established. In addition, the sample covered a narrow age range. Also, several variables such as dietary intake, physical activity and maturity stages were collected via self-completed questionnaire, which may be a limitation due to the potential for misreporting. However, no method is without its limitations and this method was pilot tested on adolescents, it was expected that it would be a reasonable approach. First, 7-day dietary record seemed the most appropriate in view of adolescents' memory processing capability ${ }^{30}$ and because other approaches such as indirect calorimetry were not possible in this population-based study. Second, the translated PAQ-C had previously been validated in a local setting. ${ }^{40}$ Third, the self-reported puberty stage has been found to be reliable in a school-based survey with a weighted kappa coefficient of 0.68 for males and females. ${ }^{62}$

\section{CONCLUSION}

The findings of this study suggest that muscle strength is associated with energy intake and physical activity among males. However, this relationship was not found in females. This difference requires further investigation in order to gain better understanding of the issues affecting muscle strength so as to improve the provision of nutritional and physical activity strategies for the adolescent muscular health of both genders.

\author{
Author affiliations \\ ${ }^{1}$ Faculty of Medicine, Department of Social and Preventive Medicine, University of \\ Malaya, Kuala Lumpur, Malaysia \\ ${ }^{2}$ School of Health Sciences, Nutrition and Dietetics Department, International \\ Medical University, Kuala Lumpur, Malaysia \\ ${ }^{3}$ Faculty of Medicine, Centre for Epidemiology and Evidence-Based Practice and \\ Department of Social and Preventive Medicine, University of Malaya, Kuala Lumpur, \\ Malaysia \\ ${ }^{4}$ Faculty of Medicine, Department of Paediatrics, University of Malaya, Kuala \\ Lumpur, Malaysia \\ ${ }^{5}$ Nutrition, Harvard University T.H. Chan School of Public Health, Boston, \\ Massachusetts, USA \\ ${ }^{6}$ Department of Nutrition, Faculty of Public Health, Universitas Airlangga, Surabaya, \\ East Java, Indonesia
}

\section{Twitter@AmHazreen}

Acknowledgements The authors would like to thank Associate Professor Dr Mohd Nahar Azmi Mohamed, Professor Dr Tin Tin Su and Dr 'Abqariyah Binti Yahya for the support and guidance.

Contributors NAK, MHA and NNH carried out the data analysis. NAK drafted the manuscript. MHA contributed to the study design and both MHA and MYJ involved with data collection. All authors contributed to the final manuscript write-up.
Funding This study was supported by funding received from the University Malaya's Research Programme (UMRP022A-14HTM) and Postgraduate Research Fund (PG026-2016A).

\section{Competing interests None declared.}

Patient consent for publication Parental/guardian consent obtained.

Ethics approval Ethics Committee of the University Malaya Medical Centre (MEC ref. no. 896.34).

Provenance and peer review Not commissioned; externally peer reviewed. Data sharing statement No additional data are available.

Open access This is an open access article distributed in accordance with the Creative Commons Attribution Non Commercial (CC BY-NC 4.0) license, which permits others to distribute, remix, adapt, build upon this work non-commercially, and license their derivative works on different terms, provided the original work is properly cited, appropriate credit is given, any changes made indicated, and the use is non-commercial. See: http://creativecommons.org/licenses/by-nc/4.0/.

\section{REFERENCES}

1. Ortega FB, Silventoinen K, Tynelius $P$, et al. Muscular strength in male adolescents and premature death: cohort study of one million participants. BMJ 2012;345:e7279.

2. Cohen DD, López-Jaramillo P, Fernández-Santos JR, et al. Muscle strength is associated with lower diastolic blood pressure in schoolchildren. Prev Med 2017;95:1-6.

3. Steene-Johannessen J, Anderssen SA, Kolle E, et al. Low muscle fitness is associated with metabolic risk in youth. Med Sci Sports Exerc 2009;41:1361-7.

4. Blakeley CE, Van Rompay MI, Schultz NS, et al. Relationship between muscle strength and dyslipidemia, serum $25(\mathrm{OH}) \mathrm{D}$, and weight status among diverse schoolchildren: a cross-sectional analysis. BMC Pediatr 2018;18:23.

5. Ruiz JR, Castro-Piñero J, Artero EG, et al. Predictive validity of health-related fitness in youth: a systematic review. Br J Sports Med 2009;43:909-23.

6. Thivel D, Ring-Dimitriou S, Weghuber D, et al. Muscle strength and fitness in pediatric obesity: a systematic review from the European Childhood Obesity Group. Obes Facts 2016;9:52-63.

7. Timpka S, Petersson IF, Zhou C, et al. Muscle strength in adolescent men and future musculoskeletal pain: a cohort study with 17 years of follow-up. BMJ Open 2013;3:e002656.

8. Silva DAS, Pelegrini A, de Castro JAC, et al. Low handgrip strength levels among adolescents in a city in southern Brazil. J Bodyw Mov Ther 2017;21:884-9.

9. Cohen DD, Voss C, Taylor MJ, et al. Ten-year secular changes in muscular fitness in English children. Acta Paediatr 2011;100:e17 5-e177.

10. Dos Santos FK, Prista A, Gomes TN, et al. Secular trends in physical fitness of Mozambican school-aged children and adolescents. Am J Hum Biol 2015;27:201-6.

11. Huotari PR, Nupponen $\mathrm{H}$, Laakso L, et al. Secular trends in muscular fitness among Finnish adolescents. Scand J Public Health 2010;38:739-47.

12. Silverman IW. The secular trend for grip strength in Canada and the United States. J Sports Sci 2011;29:599-606.

13. Otero J, Cohen DD, Herrera VM, et al. Sociodemographic factors related to handgrip strength in children and adolescents in a middle income country: The SALUS study. Am J Hum Biol 2016;29.

14. Majid HA, Noran H, Jalaludin MY, et al. Poster Communications ICD Granada 2016. 17th International Congress of Dietetics 2016. Granada, Spain: Spanish Journal of Human Nutrition and Dietetics, 2016.

15. Gracia-Marco L, Bel-Serrat S, Cuenca-Garcia M, et al. Amino acids intake and physical fitness among adolescents. Amino Acids 2017;49:1041-52.

16. Anjum SN, Choudary P, Dimri R, et al. Comparative evaluation of grip and pinch strength in an Asian and European population. Hand Therapy 2012;17:11-14.

17. Keats E C, Rappaport Al, Jain R, et al; Diet and eating practices among adolescent girls in low- and middle-income countries: a systemic review. Arlington, VA: Strengthening Partnerships, Results, and Innovations in Nutrition Globally (SPRING) project, 2017.

18. World Health Organization. Prevalence of insufficient physical activity. 2018;2018. http://www.who.int/gho/ncd/risk_factors/physical_ activity_text/en/ 
19. Martinez-Gomez D, Eisenmann JC, Gomez-Martinez S, et al. Associations of physical activity and fitness with adipocytokines in adolescents: the AFINOS Study. Nutr Metab Cardiovasc Dis 2012;22:252-9.

20. Agostinis-Sobrinho C, Abreu S, Moreira C, et al. Muscular fitness, adherence to the Southern European Atlantic Diet and cardiometabolic risk factors in adolescents. Nutr Metab Cardiovasc Dis 2017;27:695-702.

21. Silva DAS, Martins PC. Impact of physical growth, body adiposity and lifestyle on muscular strength and cardiorespiratory fitness of adolescents. J Bodyw Mov Ther 2017;21:896-901.

22. Kulkarni B, Kuper H, Radhakrishna KV, et al. The association of early life supplemental nutrition with lean body mass and grip strength in adulthood: evidence from APCAPS. Am J Epidemio/ 2014;179:700-9.

23. Lambourne $\mathrm{K}$, Washburn RA, Lee J, et al. A 6-month trial of resistance training with milk supplementation in adolescents: effects on body composition. Int J Sport Nutr Exerc Metab 2013;23:344-56.

24. Argilés JM, Campos N, Lopez-Pedrosa JM, et al. Skeletal muscle regulates metabolism via interorgan crosstalk: roles in health and disease. J Am Med Dir Assoc 2016;17:789-96.

25. Otero J, Cohen DD, Herrera VM, et al. Sociodemographic factors related to handgrip strength in children and adolescents in a middle income country: The SALUS study. Am J Hum Biol 2017;29:e22896.

26. Hazreen MA, Su TT, Jalaludin MY, et al. An exploratory study on risk factors for chronic non-communicable diseases among adolescents in Malaysia: overview of the Malaysian Health and Adolescents Longitudinal Research Team study (The MyHeART study). BMC Public Health 2014;14(Suppl 3):S6.

27. Wind AE, Takken T, Helders PJ, et al. Is grip strength a predictor for total muscle strength in healthy children, adolescents, and young adults? Eur J Pediatr 2010;169:281-7.

28. Pillsbury L, Oria M, Pate R. Fitness measures and health outcomes in youth: National Academies Press, 2013.

29. Malaysian Health and Adolescents Longitudinal Research Team (MyHeART) Study Handbook. Kuala Lumpur: University of Malaya Press, 2019.

30. Burrows TL, Martin RJ, Collins CE. A systematic review of the validity of dietary assessment methods in children when compared with the method of doubly labeled water. J Am Diet Assoc 2010;110:1501-10.

31. Willett W. Nutritional epidemiology: Oxford University Press, 2012.

32. Livingstone MB, Prentice AM, Coward WA, et al. Validation of estimates of energy intake by weighed dietary record and diet history in children and adolescents. Am J Clin Nutr 1992;56:29-35.

33. Livingstone MB, Robson PJ, Wallace JM. Issues in dietary intake assessment of children and adolescents. Br J Nutr 2004;92(S2):S2 13-S222.

34. Tee ES, Noor MI, Azudin MN, et al. The Nutrient Composition of Malaysian Food. 4th edn, 1997.

35. Day S, Fayers P, Harvey D. Double data entry: what value, what price? Control Clin Trials 1998;19:15-24.

36. Berkey CS, Rockett HR, Field AE, et al. Activity, dietary intake, and weight changes in a longitudinal study of preadolescent and adolescent boys and girls. Pediatrics 2000;105:e56.

37. Kowalski KC, Crocker PRE, Faulkner RA. Validation of the Physical Activity Questionnaire for Older Children. Pediatr Exerc Sci 1997;9:174-86.

38. Dan SP, Mohd NM, Zalilah MS. Determination of factors associated with physical activity levels among adolescents attending school in Kuantan, Malaysia. Malays J Nutr 2011;17:175-817.

39. Nor Aini J, Poh BK, Chee WS. Validity of a children's physical activity questionnaire (CPAQ) for the study of bone health. Pediatr Int 2013;55:223-8

40. Dan SP, Mohd Nasir MT, Zalilah MS. Sex and ethnic differentials in physical activity levels of adolescents in Kuantan. Malays $\mathrm{J}$ Nutr 2007;13:109-20.

41. Crocker PR, Bailey DA, Faulkner RA, et al. Measuring general levels of physical activity: preliminary evidence for the Physical
Activity Questionnaire for Older Children. Med Sci Sports Exerc 1997:29:1344-9.

42. Pelegrini A, Silva DAS, de Lima Silva JMF, et al. Anthropometric indicators of obesity in the prediction of high body fat in adolescents. Revista Paulista de Pediatria 2015;33:56-62.

43. Sandercock GRH, Lobelo F, Correa-Bautista JE, et al. The relationship between socioeconomic status, family income, and measures of muscular and cardiorespiratory fitness in Colombian schoolchildren. J Pediatr 2017;185:81-7.

44. Foo LH, Zhang Q, Zhu K, et al. Low vitamin D status has an adverse influence on bone mass, bone turnover, and muscle strength in Chinese adolescent girls. J Nutr 2009;139:1002-7.

45. Kamarul T, Ahmad TS, Loh WY. Hand grip strength in the adult Malaysian population. J Orthop Surg 2006;14:172-7.

46. Trudeau F, Shephard RJ, Arsenault F, et al. Tracking of physical fitness from childhood to adulthood. Can J Appl Physiol 2003;28:257-71.

47. Su TT, Sim PY, Nahar AM, et al. Association between self-reported physical activity and indicators of body composition in Malaysian adolescents. Prev Med 2014;67:100-5.

48. Abdul Majid H, Ramli L, Ying SP, et al. Dietary intake among adolescents in a middle-income country: an outcome from the Malaysian Health and Adolescents Longitudinal Research Team Study (the MyHeARTs Study). PLoS One 2016;11:e0155447.

49. Breen L, Phillips SM. Interactions between exercise and nutrition to prevent muscle waste during ageing. Br J Clin Pharmacol 2013;75:708-15.

50. Strasser B, Volaklis K, Fuchs D, et al. Role of dietary protein and muscular fitness on longevity and aging. Aging Dis 2018;9:119-32.

51. Freedman DS, Sherry B. The validity of BMI as an indicator of body fatness and risk among children. Pediatrics 2009;124(Supplement 1):S23-S34.

52. Tomlinson DJ, Erskine RM, Morse Cl, et al. The impact of obesity on skeletal muscle strength and structure through adolescence to old age. Biogerontology 2016;17:467-83.

53. Ceschia A, Giacomini S, Santarossa S, et al. Deleterious effects of obesity on physical fitness in pre-pubertal children. Eur J Sport Sci 2016;16:1-8.

54. Little MA. Grip strength and body composition in Turkana pastoralist children and adolescents. Am J Hum Biol 2017;29:e22922.

55. Faigenbaum AD, Kraemer WJ, Blimkie CJ, et al. Youth resistance training: updated position statement paper from the national strength and conditioning association. $J$ Strength Cond Res 2009;23:S60-S79.

56. McComas AJ, Sica RE, Petito F. Muscle strength in boys of different ages. J Neurol Neurosurg Psychiatry 1973;36:171-3.

57. Wu G. Dietary protein intake and human health. Food Funct 2016;7:1251-65.

58. RÁ M, Cavalli AS, Ribeiro JAB, et al. Association between handgrip strength and physical activity in hypertensive elderly individuals. Revista Brasileira de Geriatria e Gerontologia 2015;18:881-91.

59. Ravisankar P, Madanmohan, Udupa K, et al. Correlation between body mass index and blood pressure indices, handgrip strength and handgrip endurance in underweight, normal weight and overweight adolescents. Indian J Physiol Pharmacol 2005;49:455.

60. Ploegmakers JJ, Hepping AM, Geertzen JH, et al. Grip strength is strongly associated with height, weight and gender in childhood: a cross sectional study of 2241 children and adolescents providing reference values. J Physiother 2013;59:255-61.

61. Jürimäe $T$, Hurbo $T$, Jürimäe J. Relationship of handgrip strength with anthropometric and body composition variables in prepubertal children. Homo 2009;60:225-38.

62. Jaruratanasirikul S, Kreetapirom P, Tassanakijpanich N, et al. Reliability of pubertal maturation self-assessment in a school-based survey. J Pediatr Endocrinol Metab 2015;28:367-74. 